\title{
Purification of immunosuppressive factor from Capnocytophaga ochracea
}

\author{
K. OCHIAI, H. SENPUKU* and T. KURITA-OCHIAI
}

Department of Microbiology, Nihon University, School of Dentistry at Matsudo, Chiba 271 and *Department of Oral Science, National Institute of Infectious Disease, Shinjuku-ku, Tokyo 162, Japan

\begin{abstract}
Capnocytophaga, one of the genera of oral bacteria, has been implicated in the pathogenesis of several diseases, including endocarditis, septicaemia and disorders of the oral cavity such as abscesses and periodontal disease. This study examined sonic extracts (SE) of Capnocytophaga strains for their ability to alter lymphocyte function. The SE of tested Capnocytophaga caused dose-dependent suppression of spleen cells in response to mitogen. This suppressive effect was heat-labile and sensitive to the proteolytic enzyme pronase $E$. The suppressive factor (SF) was purified from SE of $C$. ochrasea by a combination of ultrogel-AcA34, high-pressure liquid DEAE ion-exchange chromatography and hydroxyapatite columns, which revealed a single band of $14 \mathrm{kDa}$ by SDS-PAGE. Rabbit anti-serum against the purified SF inhibited the immunosuppression induced by SE of $C$. ochracea with the recovery of lymphocyte proliferation.
\end{abstract}

\section{Introduction}

The genus Capnocytophaga is part of the normal oral microflora found in the absence of oral disease [1]. Capnocytophaga spp. frequently have been isolated in large numbers from peiodontal lesions of patients with localised juvenile periodontitis and other forms of periodontal disease [2-4]. An animal study with Capnocytophaga-mono-infected animals has clearly revealed its periodontopathic potential [5].

Dental plaque is extremely dense in bacterial cell content because of frequent interbacterial aggregations [6]. C. ochracea exhibits co-aggregation mediated by lectin-carbohydrate interaction. Furthermore, co-aggregated bacterial cells exhibit resistance to phagocytosis and the bactericidal action of polymorphonuclear leucocytes (PMNLs) [7]. As Capnocytophaga spp. can colonise periodontal pockets and possibly invade the surrounding tissue, investigation of the organism's ability to resist host defences is important for an understanding of the bacterial aetiology of periodontal disease and other infections. Capnocytophaga spp. also have the ability to inhibit the proliferation of human fibroblasts and promote the release of lysosomal enzyme from PMNLs, that contribute to the infection and the

Received 12 May 1997; revised version accepted 28 March 1998.

Corresponding author: Dr K. Ochiai. destruction of gingival tissue [8]. Previous work has suggested that Capnocytophaga spp. cause neutrophil abnormalities in morphology and locomotion [9] and release of the products that inhibit neutrophil chemotaxis in vitro [10]. Moreover, Capnocytophaga spp. can degrade IgA and IgG [11].

Recently, several reports have described periodontopathic bacteria, such as Actinobacillus $[12,13]$ and Capnocytophaga spp. as the cause of bacteraemia and septicaemia in non-compromised and compromised hosts [14-17].

Several investigators have reported that some periodontopathic bacteria can suppress immune responses [18]. However, there is little information on the pathogenic potential of immunosuppressive substances in any periodontal disease.

Studies in this laboratory have investigated the immunoadjuvant effects of periodontopathic bacteria and the kinetics and the immunological role of immunosuppressive factor (SF) produced by these bacteria [19]. Previous reports showed that $A$. actinomycetemcomitans produces a low mol.wt SF and that it affects $\mathrm{CD} 4 / \mathrm{CD} 8$ ratios and cytokine production [20-22]. The sonic extract (SE) from the cytoplasmic soluble fraction from $C$. ochracea also suppresses immunoglobulin production and causes a CD4/CD8 ratio disorder [23]. In the present study the SF from the cytoplasmic soluble fraction of 
C. ochracea was purified by extensive column chromatography and examined for the suppression of proliferation of murine spleen cells.

\section{Materials and methods}

\section{Bacterial strains and growth conditions}

C. ochracea ATCC 33563 and C. sputigena ATCC 33123 were obtained from the American Type Culture Collection (Rockville, MD, USA). Porphyromonas gingivalis FDC 381 was also employed as a representative strain of periodontopathic bacteria in this study. The cells were grown in Brain Heart Infusion (BHI) Broth (Difco) supplemented with haemin $5 \mu \mathrm{g} / \mathrm{ml}$ and menadione $0.4 \mu \mathrm{g} / \mathrm{ml}$ in an anaerobic system (Model 1024, Forma Scientific, Marietta, OH, USA) for 2 days.

\section{SE preparation}

Micro-organisms were harvested by centrifugation $(10000 \mathrm{~g})$, then washed three times with phosphatebuffered saline (PBS, $\mathrm{pH}$ 7.2). SE from the harvested bacterial cells was prepared by a method reported previously [19]. Briefly, the bacterial cells were resuspended in PBS and sonicated for $45 \mathrm{~min}$ on ice with a sonicator (Ohtake Works, Tokyo, Japan). Disruption of the bacteria was confirmed by microscopy. The samples were centrifuged at $8000 \mathrm{~g}$ for $30 \mathrm{~min}$, and the cell-free supernate was stored at $-20^{\circ} \mathrm{C}$ until used for the experiments. The protein concentrations in the SE were estimated with the BioRad protein assay (BioRad, Richmond, CA, USA). The following SE preparation was also employed for some experiments: SE in $50 \mathrm{~mm}$ potassium phosphate buffer $\left(\mathrm{pH} \mathrm{7.2)}\right.$ was heated for $10 \mathrm{~min}$ at $100^{\circ} \mathrm{C}$ or treated with pronase $\mathrm{E}$ (Kaken Kogyo Ltd, Tokyo, Japan) for $24 \mathrm{~h}$ at $37^{\circ} \mathrm{C}$. After treatment, the preparations were dialysed against distilled water. Polymixin B (Sigma)-treated $\mathrm{SE}\left(37^{\circ} \mathrm{C}, 30 \mathrm{~min}\right)$ was also prepared to study the effect of lipopolysaccharides (LPS) in SE.

\section{Mice}

$\mathrm{C} 3 \mathrm{H} / \mathrm{HeN}$ mice aged $7-8$ weeks were obtained from Shizuoka Experimental (Hamamatsu, Japan) and LPSlow responder $\mathrm{C} 3 \mathrm{H} / \mathrm{HeJ}$ mice were obtained from Nihon-Clea (Tokyo, Japan). These mice were maintained in horizontal laminar flow cabinets and provided with sterile food and water ad libitum and were used at 8-9 weeks of age.

\section{Proliferation assay}

Spleen cells from $\mathrm{C} 3 \mathrm{H} / \mathrm{HeN}$ mice were washed and resuspended in RPMI 1640 supplemented with fetal calf serum 5\%, $2.0 \mathrm{mM}$ L-glutamine, kanamycin $0.2 \mathrm{mg} / \mathrm{ml}$ and $15 \mathrm{mM} \mathrm{N}$-2-hydroxyethylpiperazine-N2-ethansulphonic acid (HEPES) buffer ( $\mathrm{pH} 7.2$ ), and adjusted to $3.5 \times 10^{6}$ viable cells $/ \mathrm{ml}$ before culture.
Lymphoid cells were cultured in triplicate in a 96-well microculture plate in a total volume of $0.2 \mathrm{ml}$ of medium containing either Con A (Sigma) $0.5 \mu \mathrm{g}$ or LPS (Sigma) $1.0 \mu \mathrm{g}$. Different concentrations of SE were added to these samples and cells were incubated for $72 \mathrm{~h}$ at $37^{\circ} \mathrm{C}$ in humidified air containing $\mathrm{CO}_{2} 5 \%$. Cultures were pulsed with $3.7 \mathrm{kBq}$ of $\left[{ }^{3} \mathrm{H}\right]$ thymidine $\left(\left[{ }^{3} \mathrm{H}\right] \mathrm{TdR}\right.$, Amersham, Buckinghamshire) during the final $6 \mathrm{~h}$ of the inoculation. After the labelling period, cells were harvested on to glass fibre filters with a multiple-cell harvester type MHCMO-YR 1162 (Biotec, Tokyo, Japan). The filters were dried, placed in vials with scintillation fluid and analysed with a scintillation counter (type LSC-673, Aloka, Tokyo, Japan). Each assay was repeated at least three times.

\section{Extraction of LPS}

Phenol-water-extracted LPS and butanol-water-extracted LPS were also prepared by the methods described previously [24, 25]. Briefly, lyophilised cells $(10 \mathrm{~g})$ were suspended in pyrogen-free water and phenol $90 \%$. The mixture was stirred vigorously at $65^{\circ} \mathrm{C}$ for $20 \mathrm{~min}$ and then centrifuged at $7000 \mathrm{~g}$ for $20 \mathrm{~min}$. The aqueous phase was removed, and the phenol phase and insoluble precipitate were reextracted with water. The aqueous phase was dialysed extensively against distilled water, lyophilised and termed PW-LPS. The same weight of lyophilised cells was suspended in $\mathrm{NaCl} 0.85 \%$ in water. An equal volume of water-saturated butanol was added, and the aqueous phase was obtained after stirring the reaction mixture and centrifugation. The combined extracts of the aqueous phase were dialysed against distilled water and lyophilised. This was termed BW-LPS.

\section{Preparation of fractions from bacterial cells}

Cells of each strain (wet weight $17.5 \mathrm{~g}$ ) were resuspended in PBS and homogenised with glass beads $(0.10-0.11 \mathrm{~mm}, 40 \mathrm{~g})$ in a Braun cell homogeniser (Model MSK, B Braun, Germany). Samples were kept standing at room temperature for $10 \mathrm{~min}$; suspensions were then centrifuged at $8000 \mathrm{~g}$ for $20 \mathrm{~min}$. Each supernate was obtained as a cytoplasmic fraction (CPF) after centrifugation at $100000 \mathrm{~g}$ for $60 \mathrm{~min}$ and dialysis against distilled water followed by lyophilisation. The precipitate was resuspended in $0.05 \mathrm{M}$ phosphate buffer (pH 7.0) and stirred for $30 \mathrm{~min}$ at room temperature with the addition of an equal amount of buffer containing n-lauroylsarcosine (N-dodecanol-N methylglycine) $2 \%$. The supernate was obtained by centrifugation as described above. This was termed the inner membrane fraction (IMF) after dialysis against distilled water and lyophilisation.

\section{Purification of SF}

To prepare the cytoplasmic fraction, the homogenised fraction was further centrifuged at $100000 \mathrm{~g}$ for 
$60 \mathrm{~min}$. The supernates containing cytoplasm were dialysed extensively against $20 \mathrm{mM}$ Tris buffer $(\mathrm{pH}$ 8.2). The CPF from $C$. ochracea was dialysed against $10 \mathrm{mM}$ Tris buffer $(\mathrm{pH} 7.4)$ and concentrated $(\times 10)$ by Centricon 10 (Amicon, Lexington, MA, USA) and applied to an Ultrogel-AcA34 column, $6 \times 40 \mathrm{~cm}$, (IBF Biotechnics, France) pre-equilibrated with the same buffer. The column was then washed extensively. Ten$\mathrm{ml}$ fractions were collected and monitored for UV absorbance and immunosuppressive activity (reduction of mitogen-induced $\left[{ }^{3} \mathrm{H}\right]$ TdR incorporation by LPS). Active fractions were pooled, dialysed against $10 \mathrm{~mm}$ Tris buffer ( $\mathrm{pH} \mathrm{7.4)}$ and then applied to an HPLCDEAE 5PW (Toso, Tokyo, Japan) column pre-equilibrated in the same buffer. The column was then extensively washed and eluted with a linear $\mathrm{NaCl}$ gradient $(0-0.5 \mathrm{M})$. Active fractions were pooled, concentrated by membrane filtration (Centricon 10; Amicon) and applied to an HPLC-hydroxyapatite-MP column, $8.8 \times 10 \mathrm{~cm}$, (Kanto Chemical, Tokyo, Japan). The column was washed extensively with the same buffer and eluted with a linear $\mathrm{KH}_{2} \mathrm{PO}_{4}-\mathrm{K}_{2} \mathrm{HPO}_{4}$ gradient $(0-0.5 \mathrm{M})$. Active immunosuppressive fractions were pooled and concentrated after dialysis.

\section{$S D S-P A G E$}

Samples at each step in the purification procedure were examined by SDS-PAGE. Samples were loaded at concentrations of $10-50 \mu \mathrm{g}$ of protein/lane. Electrophoresis was performed at $15 \mathrm{~mA}$ for $60 \mathrm{~min}$ with resolving $15 \%$ and stacking $4 \%$ gels. Proteins were stained with Coomassie Brilliant Blue R-250. A low mol.-wt standard (BioRad) was used for the mol.wt estimate. The periodic acid-Schiff base method was also used for determination of the homogeneity of SF.

\section{Enzyme and heat treatments of $S F$}

The purified SF $(4.0 \mu \mathrm{g})$ in $50 \mathrm{mM}$ potassium phosphate buffer $\left(\mathrm{pH} \mathrm{7.2)}\right.$ was heated for $10 \mathrm{~min}$ at $100^{\circ} \mathrm{C}$. Pronase sensitivity was also tested by incubation of SF with pronase $\mathrm{E}$ (Kaken Kogyo) at $37^{\circ} \mathrm{C}$ for $2 \mathrm{~h}$. The enzyme was inactivated by heating for $10 \mathrm{~min}$ at $100^{\circ} \mathrm{C}$. After treatment, the preparation was dialysed against distilled water at $4^{\circ} \mathrm{C}$. The samples were tested with a mitogen-induced proliferation assay with mouse spleen cells.

\section{Preparation of anti-SF serum}

Three New Zealand White rabbits (Shizuoka Experimental, Hamamatsu, Japan) were given four subcutaneous injections with $0.1 \mathrm{ml}$ of a $1: 1$ emulsion mixture of purified SF from $C$. ochracea and complete Freund's adjuvant (Difco) on days 0 and 14 . On day 28, rabbits were boosted with an inter-muscular injection of antigen. A total of $500 \mu \mathrm{g}$ of purified SF was given to each rabbit. Serological analysis of various antigens with rabbit anti-SF serum was done by Western blotting. Anti-SF serum was obtained from these rabbits and assayed for its inhibitory action on immunosuppression against SE.

\section{Western blotting}

Antigen preparations were transferred electrophoretically to a nitrocellulose filter after SDS-PAGE separation [26]. The filter was soaked in $50 \mathrm{mM}$ Tris- $\mathrm{HCl}$ buffer ( $\mathrm{pH} 7.3$ ) containing $0.15 \mathrm{M} \mathrm{NaCl}$ and low-fat milk $5 \%$ and shaken gently for $30 \mathrm{~min}$. The strips of nitrocellulose filter were incubated with antiserum for $4 \mathrm{~h}$ at room temperature. After washing and blocking, the membrane was incubated with a solution of horseradish peroxidase-conjugated anti-rabbit $\mathrm{IgG}$ mouse monoclonal antibody (Zymed Laboratories, San Francisco, CA, USA), followed by incubation in a solution containing 4-chloro-naphthol $0.05 \%$.

\section{Statistical analysis}

Statistical analysis was performed with Student's $t$ test.

\section{Results}

\section{Effect of SE on mitogen}

SEs of tested bacteria were first examined for their ability to alter mitogen-induced spleen cell proliferation as shown in Fig. 1A and B. A low concentration $(5 \mu \mathrm{g} /$ well) of the SE from $P$. gingivalis enhanced cell proliferation induced by Con A or LPS. However, a high concentration $(20-40 \mu \mathrm{g} /$ well $)$ caused a dosedependent inhibition. Two strains of Capnocytophaga revealed a strong immunomodulative activity, even at low concentrations. In particular, C. ochracea demonstrated maximum inhibition on mitogen-induced proliferation at $5-10 \mu \mathrm{g} /$ well. The addition of this $\mathrm{SE}$ ( $5 \mu \mathrm{g} /$ well) inhibited $65.2 \%$ of mitogenic effect of Con $\mathrm{A}$ and $75.1 \%$ of LPS. Moreover, the addition of $10 \mu \mathrm{g} /$ well and $20 \mu \mathrm{g} /$ well inhibited $90.4 \%$ and $99.2 \%$ of the proliferation induced by Con A and LPS, respectively. The effect of incubation time with $\mathrm{SE}$ on the proliferation of spleen cells was also examined. Pre-incubation with SE ( $1-6 h)$ strongly inhibited the proliferation induced by LPS (data not shown). However, pre-incubation with SE did not affect the survival ratio of spleen cells which was examined by the trypan blue exclusion method (survival ratio of pre-exposed cells $>95.3 \%$ ). Therefore, the maximum inhibition dose $(20 \mu \mathrm{g})$ of SE and pre-incubation of SE and the cells for $1 \mathrm{~h}$ was selected for the following experiments.

As it was important to determine which components in SE induced suppression, two strains of Capnocytophaga that had demonstrated strong immunosuppression were selected to elucidate what the effective components in the SEs were. The heat- and pronasetreated SEs were employed in these series of 


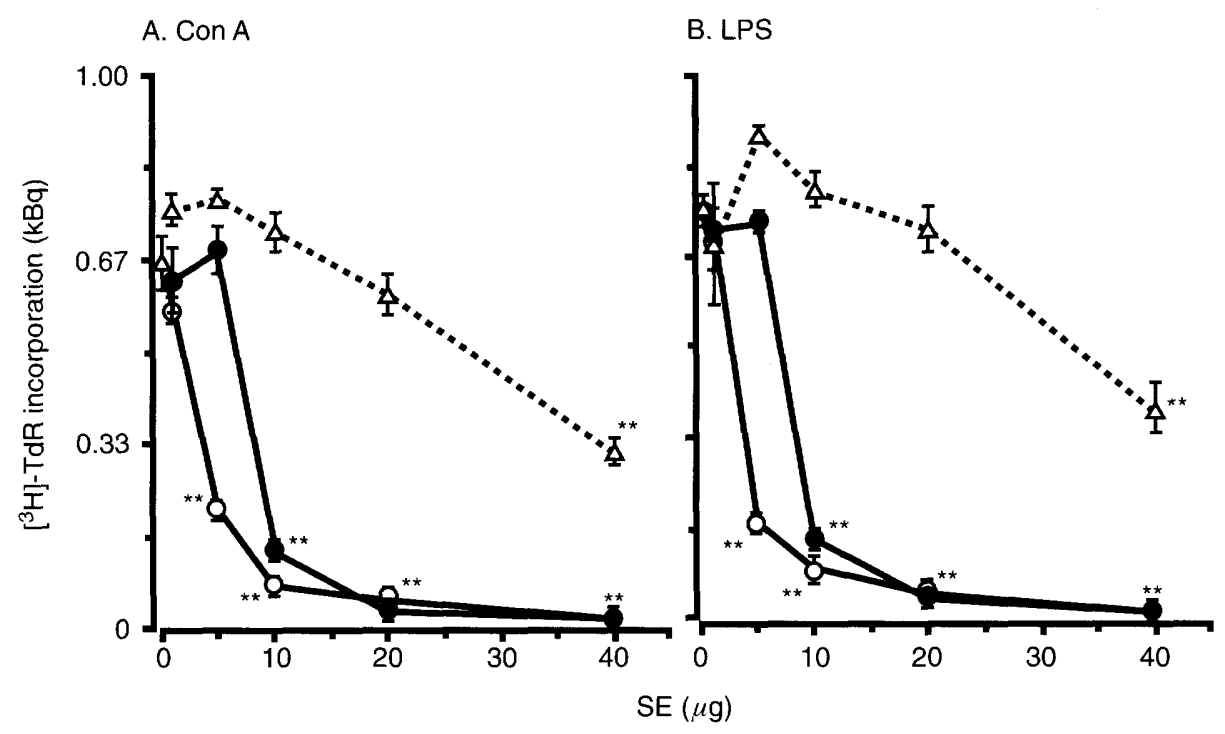

Fig. 1. Effects of SE on the mitogenicity induced by Con A and LPS. Mouse $(\mathrm{C} 3 \mathrm{H} / \mathrm{HeN})$ spleen cells were incubated at $37^{\circ} \mathrm{C}$ for $60 \mathrm{~min}$ with various amounts of SE from C. ochracea $(\bigcirc), C$. sputigena $(\bigcirc)$, P. gingivalis $(\triangle)$ followed by the addition of an optimal mitogenic dose of Con A $(0.5 \mu \mathrm{g})$ and LPS $(1 \mu \mathrm{g})$ as described in Materials and methods. $\left[{ }^{3} \mathrm{H}\right] \mathrm{TdR}$ incorporation was measured after incubation for 3 days. Points represent the mean values from three different experiments (reproducibility $81.2 \%$ ). Control values were $0.67 \mathrm{SD} 0.08 \mathrm{kBq}$ (Con A) and $0.75 \mathrm{SD} 0.11 \mathrm{kBq}$ (LPS). Vertical bars represent the SEM. Significantly different from the respective controls: ${ }^{* *} \mathrm{p}<0.01$.

experiments (Fig. 2A and B). The mitogen-induced proliferation was restored to various degrees by these treatments; heat-treatment of SE from C. ochracea produced recovery of up to $78.2 \%$ (Con A) and $90.4 \%$ (LPS) of the control, and with pronase-treatment, $85.1 \%$ (Con A) and 80.3\% (LPS) (Fig. 2A and B). Similar recoveries were obtained for SE from $C$. sputigena. Spleen cells from LPS-low responder mice, $\mathrm{C} 3 \mathrm{H} / \mathrm{HeJ}$, were also used to examine the inhibitory effect of native SE from two strains of Capnocytophaga employing the same procedure as above. Similar results were obtained with $\mathrm{C} 3 \mathrm{H} / \mathrm{HeN}$ mice (Fig. 3). SEs from strains of Capnocytophaga produced a strong suppression of $95.1-99.0 \%$ of the control, respectively, for both mitogens. Polymixin B (an LPS inhibitor) was used to elucidate the effect of LPS in SE. Polymixin B did not affect the suppression induced by these strains under the conditions of the reaction mixture containing SE $(20 \mu \mathrm{g})$ and different concentrations of polymixin B $(0.2-2.0 \mu \mathrm{g}$ ) (data not shown).

\section{Suppressive effect of prepared fractions}

Four different fractions were prepared from $C$. ochracea which strongly suppressed Con A- and LPSinduced cell proliferation (Fig. 4A and B). PW-LPS and BW-LPS did not have a strong immunomodulatory activity with either mitogen. The suppressive effect was not observed at tested concentrations of IMF. However, CPF from C. ochracea significantly suppressed Con Aand LPS-induced cell proliferation, dose dependently. Addition of $1 \mu \mathrm{g}$ of CPF caused $60.4 \%$ inhibition of cell proliferation induced by Con A and LPS, and $20 \mu \mathrm{g}$ induced $90.2 \%$ inhibition. This suppression was

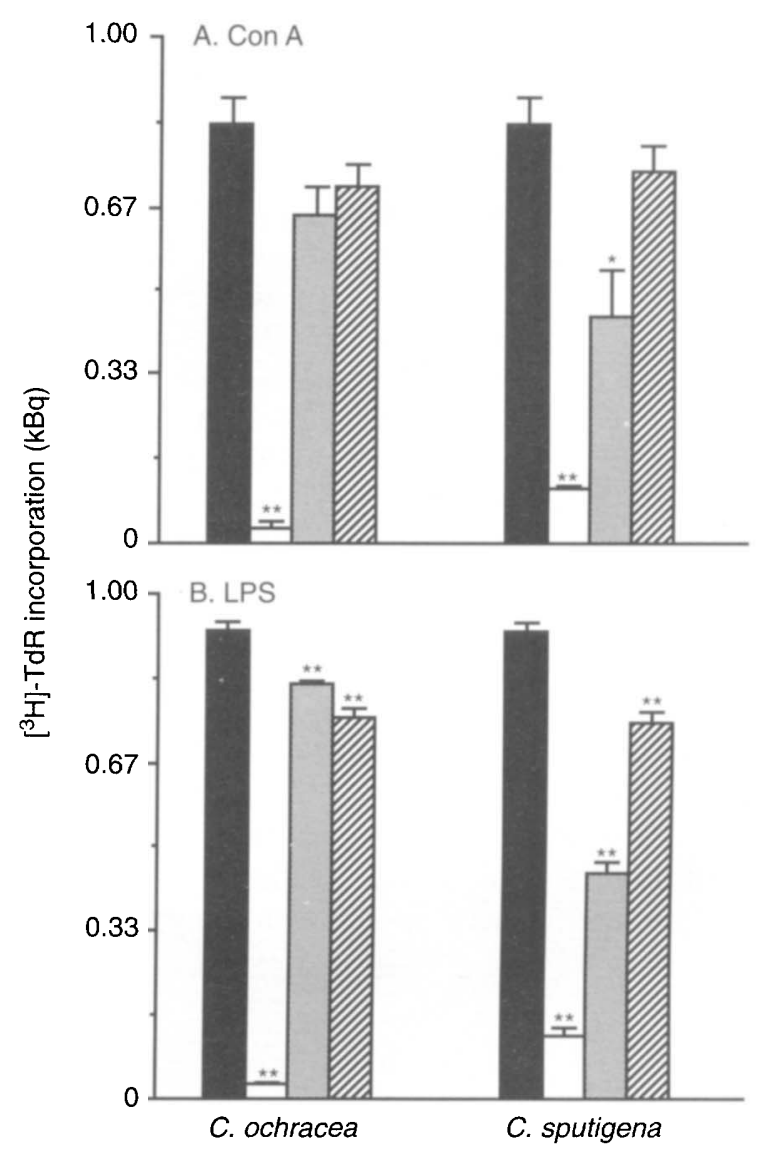

Fig. 2. Effects of heat or pronase treatment on SE from Capnocytophaga. Mouse spleen cells were incubated with heat- or pronase-treated SE $(20 \mu \mathrm{g})$ followed by the addition of an optimal mitogenic dose of Con A and LPS. $\left[{ }^{3} \mathrm{H}\right] \mathrm{TdR}$ incorporation was measured after incubation for 3 days. Bars represent the mean value and SEM.

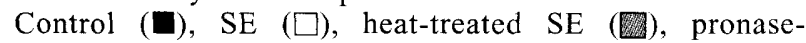
treated SE $(\mathbb{Z})$. Significantly different from the respective controls: ${ }^{*} \mathrm{p}<0.05,{ }^{*}{ }_{\mathrm{p}}<0.01$. 


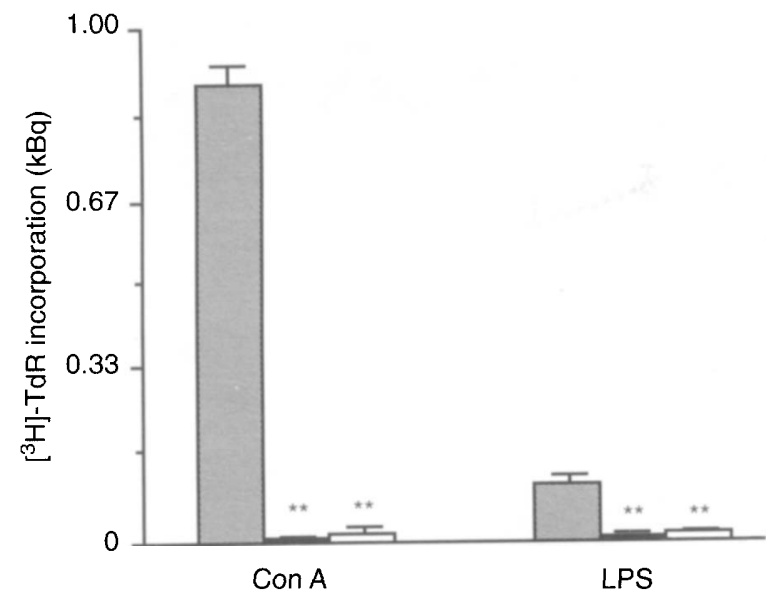

Fig. 3. Effects of SE on the mitogenicity of spleen cells from $\mathrm{C} 3 \mathrm{H} / \mathrm{HeJ}$ mice. Spleen cells were incubated with SE $(20 \mu \mathrm{g})$ followed by the addition of Con A and LPS. Control (酳), C. ochracea (ם) C. sputigena ( $\square$ ). Significantly different from the respective controls. $* * \mathrm{p}<0.01$.

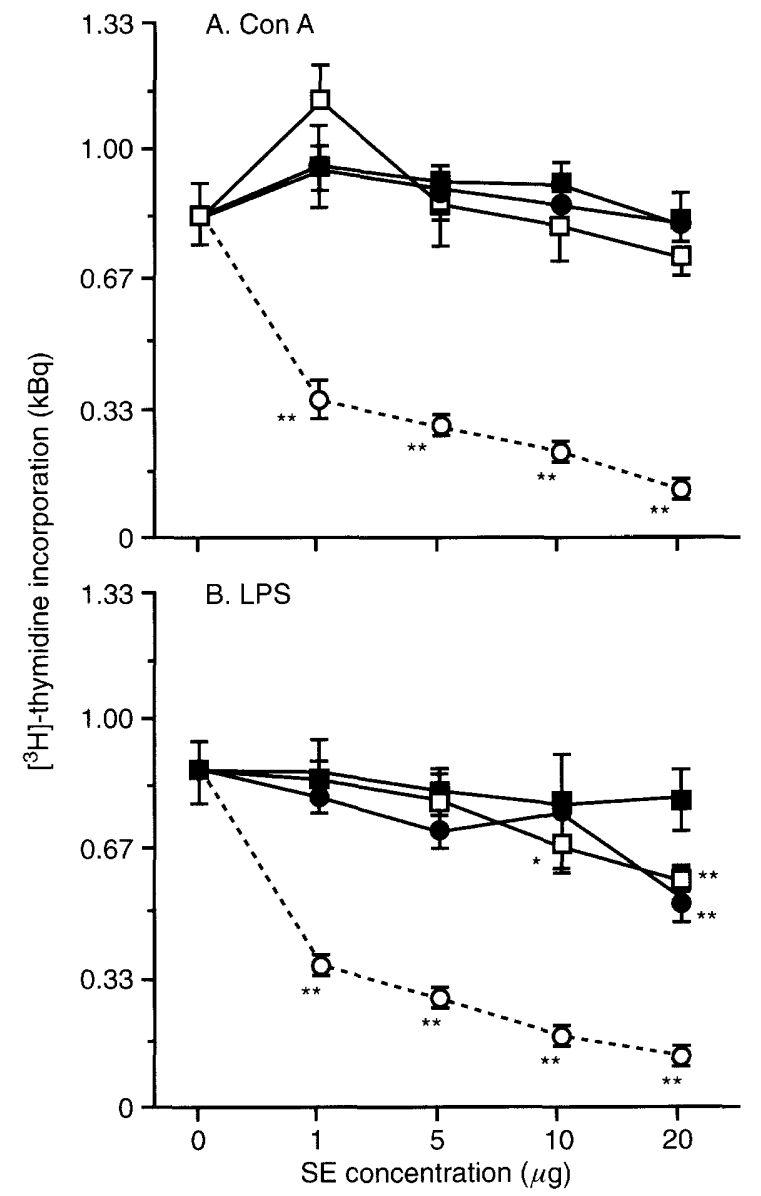

Fig. 4. Effects of various components of C. ochracea on the mitogenicity induced by Con A and LPS. Mouse spleen cells were incubated with various amounts of CPF (O), IMF (@), PW-LPS ( $\square$ ) or BW-LPS (ם) from $C$. ochracea, followed by the addition of an optimal dose of Con A and LPS. Points represent the mean value from three different experiments (reproducibility 85.4\%). Vertical bars represent the SEM. Control values were $0.81 \mathrm{SD} 0.07 \mathrm{kBq}$ (Con A) and $0.89 \mathrm{SD} 0.11 \mathrm{kBq}$ (LPS). Significantly different from the respective controls: $*_{\mathrm{p}}<0.05,{ }^{*} \mathrm{p}<0.01$. restored by either heat or pronase treatment of this CPF (data not shown). These data suggest that SF from CPF of $C$. ochracea was at least proteinaceous in part.

\section{Purification of $S F$}

$\mathrm{SF}$ from CPF was purified by a combination of gelfiltration and HPLC-DEAE. As shown in Fig. 5B, the immunosuppressive fraction was obtained as a sharp peak. However, as several other bands were detected in this sample by SDS-PAGE (Fig. 6, lane D), the concentrated active fraction was further applied to a hydroxyapatite-MP column and eluted with elution buffer. SF fractions were purified by hydroxyapatiteMP column and then subjected to SDS-PAGE analysis. This clearly revealed one band that corresponded to a mol. wt of $c .14 \mathrm{kDa}$ by Coomassie Brilliant Blue R-25 staining (Fig. 6, lane E). SF did not display any bands, as tested for the PAS method (data not shown). When this SF was examined for activity, $\mathrm{ID}_{50}$ was $16.7 \mathrm{ng}$ for LPS stimulation and $25.0 \mathrm{ng}$ for Con A.

Inhibition of immunosuppressive activity of $S F$ by rabbit anti-SF serum

The results of Western blotting showed that the rabbit anti-SF serum revealed a single band which was identical with $\mathrm{SF}$ in the lane of the DEAE-5PW preparation (Fig. 6, lane F). A difference was found in the serum titre. Therefore, the serum that possessed the highest titre was employed in the assay for inhibition of immunosuppressive activity of SF by rabbit anti-SF serum. This was examined by the proliferation assay system, stimulated with LPS. The addition of diluted anti-serum (1 in 100, 1 in 500) inhibited SE-induced immunosuppression $96.7 \%$ and $89.2 \%$, and SF-induced immunosuppression $98.2 \%$ and $96.4 \%$, respectively.

\section{Characterisation of $S F$}

The heat- and pronase-treated SF was employed in this study. The mitogen-induced proliferation was restored to various degrees by these treatments; heat treatment of SF produced recovery of up to $92.3 \%$ (Con A) and $97.6 \%$ (LPS) of the control, with pronase treatment producing recovery to $94.2 \%$ (Con A) and $98.1 \%$ (LPS).

\section{Discussion}

The Capnocytophaga spp. tested suppressed murine lymphocyte proliferative responses to mitogens with low amounts of SE (Fig. 1). In particular, C. ochracea revealed a strong immunosuppressive effect on the cell proliferation of murine spleen cells. The SF was purified from CPF by a column chromatography technique. At the first stage of the experiment, the suppressive activity of SE from $C$. ochracea decreased or was destroyed by either heat or pronase treatment 

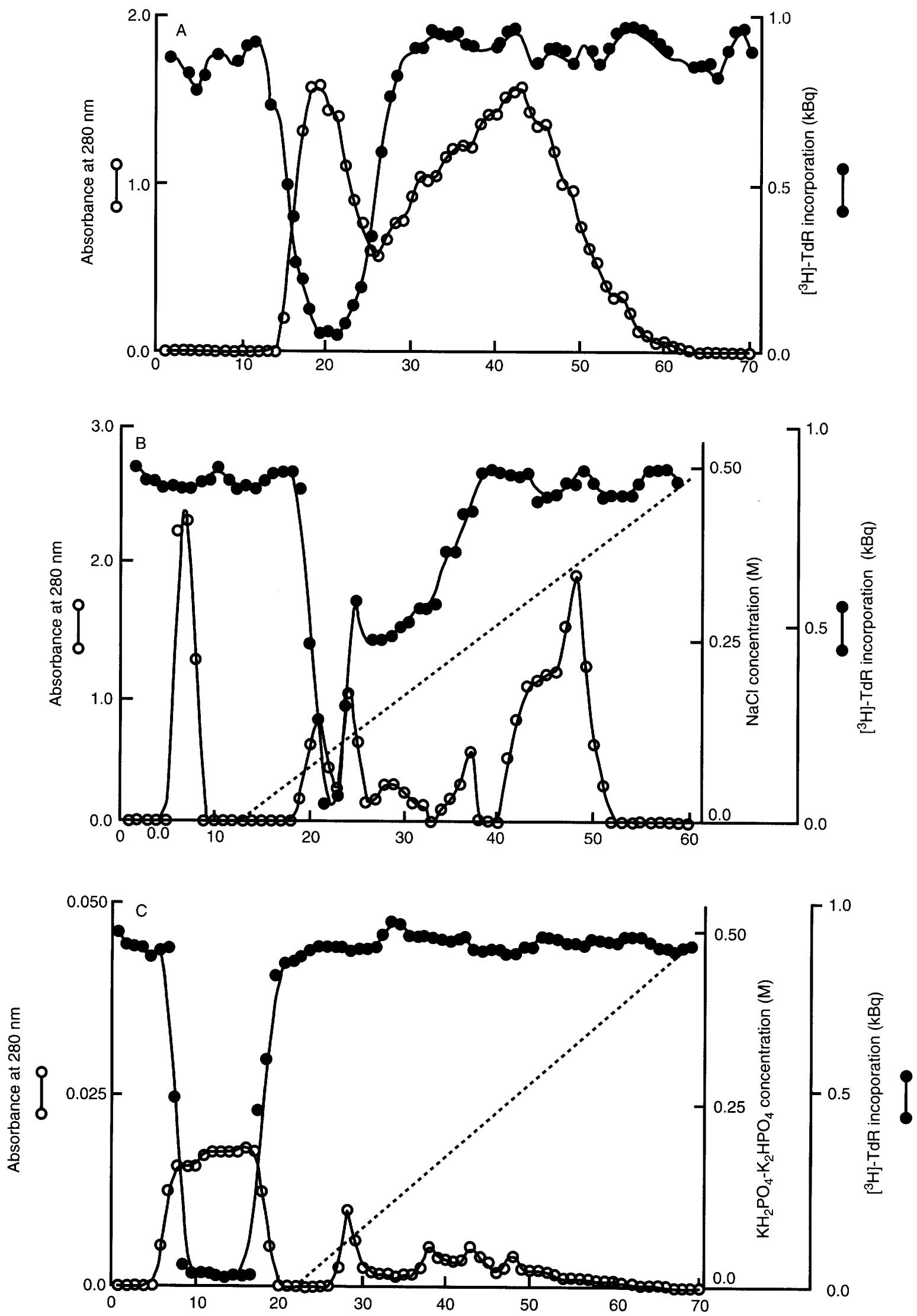

Fig. 5. Purification procedure of SF from C. ochracea. (A) CPF was applied on the Ultrogel-AcA 34 gel filtration

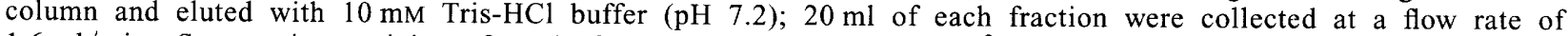
$1.6 \mathrm{ml} / \mathrm{min}$. Suppressive activity of each fraction was estimated by $\left[{ }^{3} \mathrm{H}\right] \mathrm{TdR}$ incorporation (see Materials and methods). (B) The biologically active fraction was applied to a DEAE-5PW column, and eluted by a linear gradient of $10 \mathrm{~mm}$ Tris- $\mathrm{HCl}$ buffer ( $\mathrm{pH} 7.2$ ) containing $0-0.5 \mathrm{M} \mathrm{NaCl} ; 1 \mathrm{ml}$ of each fraction was collected at a flow rate of $2 \mathrm{ml} / \mathrm{min}$. (C) The biologically active fraction was applied on a hydroxyappatite-MP column, and eluted with $10 \mathrm{mM}$ Tris- $\mathrm{HCl}$ buffer ( $\mathrm{pH} 7.2$ ) containing $0-0.5 \mathrm{M} \mathrm{KH}_{2} \mathrm{PO}_{4} ; 1 \mathrm{ml}$ of each fraction was collected at a flow rate of $2 \mathrm{ml} / \mathrm{min}$. 


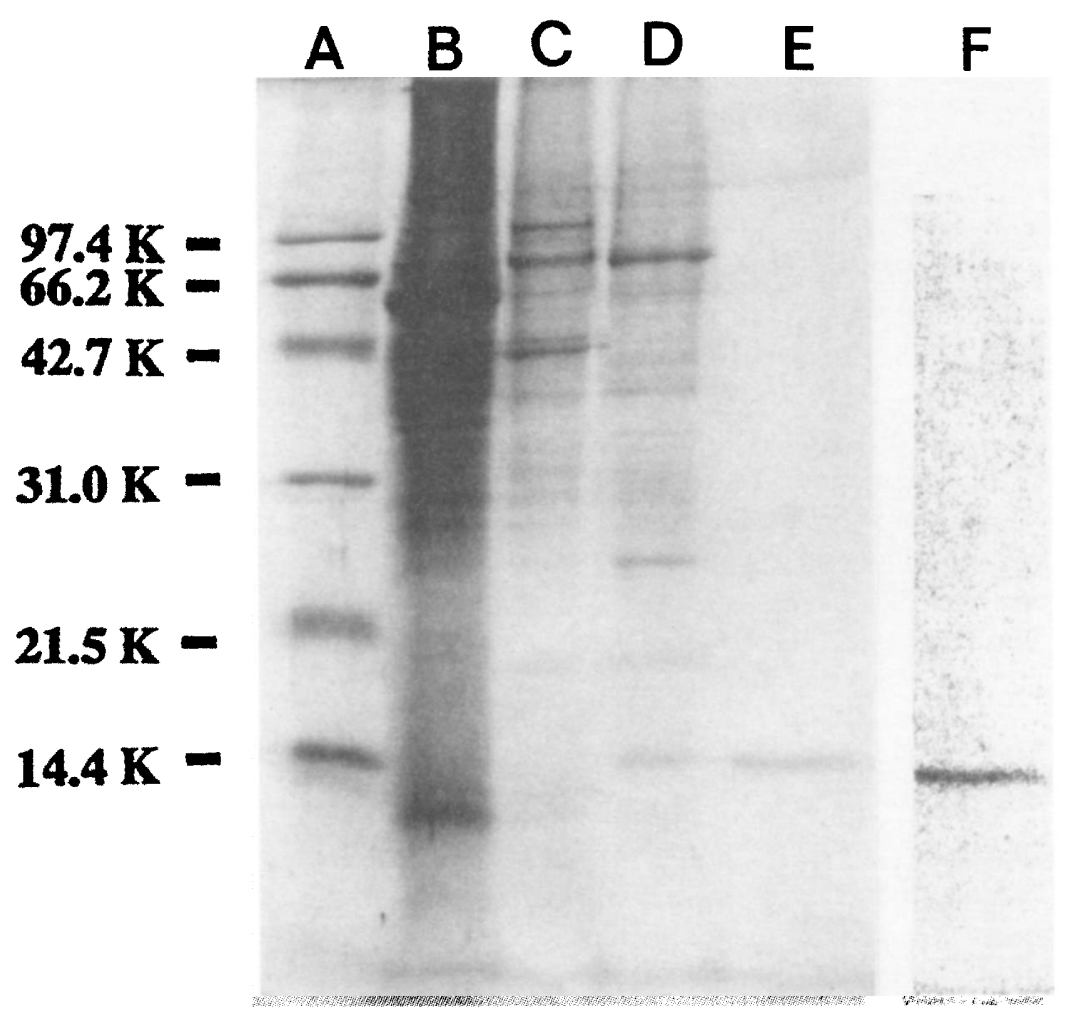

Fig. 6. SDS-PAGE analysis and Western blotting of SF from C. ochracea. Lane A, standard low mol. wt maker; B, CPF; C, Ultro-gel-AcA 34; D, DEAE-5PW; E, purified SF; F, Western blotting with DEAE-5PW and rabbit anti-SF serum.

(Fig. 2). After the purification procedure, SDS-PAGE analysis revealed that SF migrated as a single band corresponding to a molecular mass of $14 \mathrm{kDa}$. This molecule was protease and heat sensitive. The data clearly indicate that immunosuppression induced by SF from $C$. ochracea may be attributable to proteinaceous components. However, other components in SE, such as LPS, may contribute to the immunosuppression. Therefore, the following experiments were performed. LPS low responder $\mathrm{C} 3 \mathrm{H} / \mathrm{HeJ}$ mice were employed to clarify the participation of LPS in this suppression. Complete inhibition of cellular proliferation induced by either Con A or LPS was also found in $\mathrm{C} 3 \mathrm{H} / \mathrm{HeJ}$ mice (Fig. 3). Moreover, no immunomodulative activity was observed in experiments with two different preparations of LPS (PW-LPS and BW-LPS extracted from Capnocytophaga strains; Fig. 4A and B). Generally LPS demonstrates strong immunomodulative and biological activities [27]. Mixtures of different concentrations of polymixin $B$ with SE did not inhibit suppressive activity (data not shown). The data clearly indicated that LPS of Capnocytophaga strains did not have any pathogenic potential in tests for various biological activities. A previous study also reported that LPS isolated from Capnocytophaga spp. did not have any pathogenic features [28].

It has been shown previously that the suppressive effect on the murine lymphocyte mitogenic response was caused by the exopolysaccharide from $C$. ochracea [29,30]. Gormand et al. [17] reported similar inhibition of lymphocyte response to these mitogens, and the inhibition was more potent with bacterial suspension than supernate. The SF described here was located in the CPF of $C$. ochracea, suggesting that the cytoplasmic SF remained intracellular and that the bacterial suspension contained a sufficient amount of SF to inhibit lymphocyte proliferation.

Purified T or B cells were not employed in this study. Therefore, the respective effect of SF on each subset of lymphocytes cannot be explained from these data. However, pre-incubation with SF and splenic cells revealed different cell proliferation induced by Con $\mathrm{A}$ and LPS (data not shown). A decrease of CD4/CD8 ratio and lymphocyte proliferation induced by Con $A$ has been reported in an endocarditis patient with $C$. ochracea [17] and IL-2 receptor expression and Con A-induced proliferation of peripheral blood mononuclear cells were decreased during $C$. ochracea infection. Differences in response to mitogens and clinical aspects involving lymphocytes may suggest that disorder of a specific lymphocyte subset results in immunosuppression.

A. actinomycetemcomitans has been a suspected aetiological agent in localised juvenile and adult periodontitis, demonstrating a variety of virulence factors in in-vitro experiments. It can also cause disease such as bacterial endocarditis, meningitis, septicaemia and abscesses in extra-oral sites [12,13]. 
A. actinomycetemcomitans produces a protease-labile, non-cytotoxic low mol.wt (14 kDa) suppressive factor [22]. Previous studies have shown that priming with a high concentration of SE from $A$. actinomycetemcomitans induced an immunosuppressive effect on immunoglobulin production, $\mathrm{CD} 4 / \mathrm{CD} 8$ ratios and blastogenic activity to mitogen [20-22]. This inhibitory mechanism was, in part, clarified by the demonstration of suppression of IL-2 synthesis, IL-2 receptor expression and IL-6 secretion [20, 21]. Finally, A. actinomycetemcomitans produced the development of humoral or cell-mediated immune responses, or both, via the modulation of the $\mathrm{T}$-cell subset and cytokine production. The evidence found in A. actinomycetemcomitans infection indicates the possibility that similar mechanisms may exist in capnocytophaga infection.

Some of the recent cases of bacteraemia have originated from the oropharynx, although the gastrointestinal tract has been the most common source of bacteraemia [31-33]. The high frequency of systemic infection due to $C$. ochracea suggests that periodontal disease has to be considered as a possible precursor of systemic infection. It may be said that the classic source of bacteraemia in compromised or noncompromised patients, i.e., colonic microflora, appears to have been replaced by oral microflora in the anaerobic-capnophilic bacteraemias. Furthermore, another problem of concern in capnocytophaga infection is that strongly $\beta$-lactamase-positive Capnocytophaga strains have been isolated from the patients [34,35].

This study has demonstrated that $C$. ochracea produces a proteinaceous inhibitory factor. The intracellular SF and exopolysaccharide may affect the host defence system by their combined actions both locally and systemically. Therefore, studies on the effect of $\mathrm{SF}$ as immunosuppressive treatment in capnocytophaga infection would be of great interest. The exact kinetics and immunological role of purified SF on the human immune system require further study.

This work was supported in part by grants-in-aid for the Frontier Science from the Ministry of Education, Science, Sports and Culture of Japan.

\section{References}

1. Holt SC, Kinder SA. Capnocytophaga. In: Staley JT, Bryant MP, Pfennig N, Holt JG (eds) Bergey's Manual of systematic bacteriology, vol 3. Baltimore, Williams and Wilkins. 1989: 2050-2058.

2. Slots J. The predominant cultivable organisms in juvenile periodontitis. Scand J Dent Res 1976; 84: 1-10.

3. Holdeman LV, Moore WEC, Cato EP, Burmeister JA, Palcanis $\mathrm{KG}$, Ranney RR. Distribution of Capnocytophaga in periodontal microfloras. J Periodont Res 1985; 20: 475-483.

4. Haffajee AD, Socransky SS, Smith C, Dibart S. The use of DNA probes to examine the distribution of subgingival species in subjects with different levels of periodontal destruction. $J$ Clin Periodontol 1992; 19: 84-91.

5. Irving JT, Socransky SS, Tanner ACR. Histological changes in experimental periodontal disease in rays monoinfected with gram-negative organisms. J Periodont Res 1978; 13: 326-332.

6. McIntire FC. Specific surface components and microbial coaggregation. In: Mergenhagen SE, Rosan B (eds) Molecular bases of oral microbial adhesion. Washington DC, American Society for Microbiology. 1985: 153-158.

7. Ochiai K, Kurita-Ochiai T, Kamino K, Ikeda T. Effect of coaggregation on the pathogenicity of oral bacteria. $J \mathrm{Med}$ Microbiol 1993; 39: 183-190.

8. Stevens RH, Sela MN, Shapira J, Hammond BF. Detection of fibroblast proliferation inhibitory factor from Capnocytophaga sputigena. Infect Immun 1980; 27: 271-275.

9. Shurin SB, Socransky SS, Sweeney E, Stossel TP. A neutrophil disorder induced by Capnocytophaga, a dental micro-organism. $N$ Engl $J$ Med 1979; 301: 849-854.

10. Van Dyke TE, Bartholomew E, Genco RJ, Slots J, Levine MJ. Inhibition of neutrophil chemotaxis by soluble bacterial products. J Periodontol 1982; 53: 502,-508.

11. Kilian M. Degradation of immunoglobulins A1, A2, and G by suspected principal periodontal pathogens. Infect Immun 1981; 34: $757-765$.

12. Siegman-Igra Y, Schwartz D, Ophir O, Konforti N. Endocarditis caused by Actinobacillus actinomycetemcomitans. Eur $J$ Clin Microbiol 1984; 3: 556-559.

13. Verhaaren H, Claeys G, Verschraegen G, de Niel C, Leroy J, Clement D. Endocarditis from a dental focus. Importance of oral hygiene in valvar heart disease. Int $J$ Cardiol 1989; 23: 343-347.

14. Forlenza SW, Newman MG, Lipsey AI, Siegel SE, Blachman U. Capnocytophaga species: a newly recognised clinical entity in granulocytopenic patients. Lancet 1980; 115: 567-568.

15. Haulk AA, Sugar AM, Rushing JL. Capnocytophaga septicemia. $N$ Engl J Med 1980; 302: 922.

16. Parenti DM, Snydman DR. Capnocytophaga species: infections in nonimmunocompromised and immunocompromised hosts. $J$ Infect Dis 1985; 151: 140-147.

17. Gormand F, Etienne J, Rigal D, Bonnard M, Fleurette J, Beaune J. T lymphocyte disorder after Capnocytophaga ochracea endocarditis. Infection 1989; 17: 382-384.

18. Shenker BJ. Immunosuppression: an etiopathogenic mechanism. In: Guggenheim B (ed) Periodontology today. Basel, Krauger. 1988: $178-186$.

19. Ochiai K, Kurita T, Nishimura K, Ikeda T. Immunoadjuvant effects of periodontitis-associated bacteria. $J$ Periodont Res 1989; 24: 322-328.

20. Kurita-Ochiai T, Ochiai K, Ikeda T. Immunosuppressive effect induced by Actinobacillus actinomycetemcomitans: effect on immunoglobulin production and lymphokine synthesis. Oral Microbiol Immunol 1992; 7: 338-343.

21. Kurita-Ochiai T, Ochiai K, Saito N, Ikeda T. Adoptive transfer of suppressor T cells induced by Actinobacillus actinomycemcomitans regulates immune response. J Periodont Res 1994; 29: $1-8$.

22. Kurita-Ochiai $\mathrm{T}$, Ochiai $\mathrm{K}$. Immunosuppressive factor from Actinobacillus actinomycemcomitans down regulates cytokine production. Infect Immun 1996; 64: 50-54.

23. Ochiai K, Kurita-Ochiai T, Ikeda T. Effect of immunosuppression induced by periodontopathic bacteria on secondary infection. J Dent Res 1991; 70 (Special issue): 791.

24. Morrison DC, Leive L. Fractions of lipopolysaccharide from Escherichia coli O111: B4 prepared by tow extraction procedures. J Biol Chem 1975; 250: 2911-2919.

25. Westphal O, Jann K. Bacterial lipopolysaccharides. Extraction with phenol-water and further application of the procedure. Methods Carbohydr Chem 1965; 5: 83-91.

26. Towbin H, Staehelin T, Gordon J. Electrophoretic transfer of proteins from polyacrylamide gels to nitrocellulose sheets: procedure and some applications. Proc Natl Acad Sci USA 1979; 76: 4350-4354.

27. Nishihara T, Fujiwara $T$, Koga $T$, Hamada $S$. Chemical composition and immunobiological properties of lipopolysaccharide and lipid-associated proteoglycan from Actinobacillus actinomycetemcomitans. J Periodontal Res 1986; 21: 521-530.

28. Stevens RH, Sela MN, McArthur WP, Nowotny A, Hammond $\mathrm{BF}$. Biological and chemical characterization of endotoxin from Capnocytophaga sputigena. Infect Immun 1980; 27: 246-254.

29. Bolton RW, Dyer JK. Suppression of murine lymphocyte mitogen responses by exopolysaccharide from Capnocytophaga ochracea. Infect Immun 1983; 39: 476-479.

30. Bolton RW, Dyer JK, Reinhardt RA, Okano DK. Modulation of in vitro human lymphocyte responses by an exopolysaccharide 
from Capnocytophaga ochracea. $J$ Dent Res 1983; 62: 1186-1189.

31. Baquero F, Fernandez J, Dronda F et al. Capnophillic and anaerobic bacteremia in neutropenic patients: an oral source. Rev Infect Dis 1990; 12 Suppl 2: S157-S160.

32. Funada $\mathrm{H}$, Machi $\mathrm{T}$, Yoneyama $\mathrm{H}$ et al. Capnocytophaga sputigena bacteremia associated with acute leukemia. Kansenshogaku Zasshi 1993; 67: 622-628.

33. Fujita S, Ayukawa T, Tonohata A. [Identification of Capnocy- tophaga species by microplate hybridization method, and its restriction endonuclease digestion patterns.] Rinsho Byori 1995; 43: $1066-1070$.

34. Rummens IL, Gordts B, Van Landuyt HW. In vitro susceptibility of Capnocytophaga species to 29 antimicrobial agents. Antimicrob Agents Chemother 1986; 30: 739-742.

35. Arlet G, Sanson-le Pors MJ, Castaigne S, Perol Y. Isolation of a strain of $\beta$-lactamase-producing Capnocytophaga ochracea. $J$ Infect Dis 1987; 155: 1346. 